\title{
RECRIAÇÃO E CRÍTICA: POSSIBILIDADES DE TRADUÇÃO PARA O INGLÊS DO POEMA VISUAL “ODE A MARX”, DE JOAN BROSSA
}

\author{
RE-CREATION AND CRITICISM: POSSIBILITIES OF TRANSLATION INTO \\ ENGLISH OF THE VISUAL POEM "ODE A MARX” BY JOAN BROSSA
}

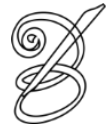 \\ Raíssa Maria Ribeiro do PRADO \\ Centro Universitário Teresa d'Ávila \\ João Francisco Pereira Nunes JUNQUEIRA ${ }^{\mathrm{ii}}$ \\ Centro Universitário Teresa d'Ávila
}

Resumo: O presente artigo tem como objetivo propor possibilidades de tradução para a língua inglesa do poema visual "Ode a Marx" (1983), do poeta catalão Joan Brossa. Foi realizada uma análise da poesia, a qual é inspirada no filósofo alemão Karl Marx (1818-1883) e traz signos que representam os pensamentos e ideais da filosofia marxista. Dessa forma, foram realizados estudos sobre o materialismo e a crítica literária marxistas, baseados em autores como Francisco Sodero Toledo (1997) e Terry Eagleton (2001). Além de aprofundamento na vida e obra do poeta Joan Brossa, mais especificamente seus poemas visuais, comprovando sua variedade artística e importância para a literatura mundial. Baseado nas teorias da tradução de Haroldo de Campos (2013), Paulo Rónai (2012) e Susan Bassnett (2003), este estudo compreende a tradução como crítica e re-criação.

Palavras-chave: Estudos da Tradução. Poesia Visual. Joan Brossa. Marxismo.

Abstract: The present article aims to propose possibilities for the translation into English of the visual poem "Ode a Marx" (1983) by Catalan poet Joan Brossa. We have conducted an analysis of the poem, which is inspired by German philosopher Karl Marx (1818-1883) and carries signs that represent the thoughts and ideals of Marxist philosophy. Thus, we have performed studies on Marxist materialism and its literary criticism, based on authors such as Francisco Sodero Toledo (1997) and Terry Eagleton (2001), in addition to a detailed account of Joan Brossa's life and work, more specifically his visual poetry. Drawing on the theories of translation of Haroldo de Campos (2013), Paulo Rónai (2012) and Susan Bassnett (2003), this study understands translation as criticism and re-creation.

Key words: Translation studies. Visual Poetry. Joan Brossa. Marxism.

RECEBIDO EM: 21/12/2017

ACEITO EM: 31/05/2018

PUBLICADO EM: julho 2018

PRADO; JUNQUEIRA. Recriação e crítica: Possibilidades de tradução para o inglês do poema visual "Ode a Marx", de Joan Brossa

Belas Infiéis, v. 7, n. 1, p. 139-160, 2018. 


\section{Introdução}

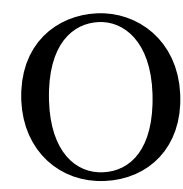

poeta e tradutor Haroldo de Campos (1921-2002), cuja obra foi nosso embasamento teórico para este trabalho, foi um importante pensador moderno das teorias da tradução. Em seu ensaio manifesto "Da Tradução como Criação e como Crítica", de 1962, aborda algumas ideias do ensaísta Albercht Fabri que propõe que a linguagem literária é sustentada pela "sentença absoluta", em que sentido e palavra não podem ser separados. Campos (2013) afirma que uma tradução literária seria sempre uma recriação, pois não se traduz apenas o significado, mas o próprio signo.

Segundo Haroldo de Campos, neste mesmo estudo, a tradução de poesia é, primeiramente, uma vivência do mundo e da técnica do que é traduzido, ou seja, o tradutor deve se empenhar em conhecer todos os aspectos do poema traduzido, assim como o seu autor e as ideias presentes na obra. Desse modo, a tradução, além de crítica, se torna uma recriação, a partir da busca por novos signos que representem os mesmos significados.

A teórica Susan Bassnett também faz afirmação semelhante quanto ao trabalho da tradução. Para Bassnett (2003), enquanto o trabalho do autor da obra original é o de dar às

140 palavras uma forma ideal e imutável, ao tradutor cabe o papel de as "libertar do confinamento da língua de partida, insuflando-lhes uma nova vida na língua para que são traduzidas". (BASSNETT, 2003, p. 8). Dessa forma, segundo a autora, a tradução passa a ser um novo “original” em outra língua.

Ainda com esse pensamento sobre a relação entre as duas línguas, o filósofo, crítico literário e teórico da tradução Antoine Berman afirma que "a essência da tradução é ser abertura, diálogo, mestiçagem, descentralização. Ela é relação, ou não é nada" (BERMAN, 2002, p. 17). Berman (2002) ainda ressalta que a tradução faz girar a obra, mostra nela outra vertente que em sua língua de partida não poderia aparecer.

Paulo Rónai, poeta e tradutor, em seu livro Escola de Tradutores (2012), aponta que modernamente concluiu-se que todo texto literário é fundamentalmente intraduzível devido à própria natureza da linguagem, pois as palavras isoladas não têm sentido sozinhas, mas têm seus significados determinados pelo contexto. Assim, traduzidas as palavras de um idioma para outro, estas seriam colocadas em um contexto totalmente diferente na língua-alvo, e como em uma obra literária "são muitas vezes as palavras que fazem brotar as ideias" (RÓNAI, 2012, p. 13), toda tradução seria uma traição. Traduttori traditori.

PRADO; JUNQUEIRA. Recriação e crítica: Possibilidades de tradução para o inglês do poema visual "Ode a Marx", de Joan Brossa 
Com base nestas constatações a respeito da tradução de textos literários, temos como objetivo neste estudo propor possibilidades de tradução como meio que possibilita uma releitura crítica e criativa da obra original. O estudo se baseia no poema visual "Ode a Marx", composto em 1983 pelo poeta catalão Joan Brossa.

Joan Brossa nasceu em Barcelona em 1919 e é um dos nomes mais importantes da literatura catalã. $\mathrm{O}$ poeta possui uma extensa e diversificada obra que inclui poesia, prosa poética, poesia visual, poemas-objeto, cinema, teatro, música, design gráfico e esculturas.

Por meio do poema "Ode a Marx”, Brossa homenageia o filósofo alemão Karl Marx (1818-1883) no centenário de sua morte, com símbolos que representam seu pensamento, sua força política e sua história. Com a criação dessa obra, o poeta traz à luz seu engajamento político e sua criatividade, pelos quais é fortemente conhecido.

Mediante estudos sobre o Marxismo, com enfoque em seu materialismo histórico e crítica literária, foi possível uma melhor compreensão a respeito da visão de Brossa ao dedicar ao filósofo esta "Ode" em formato visual.

Realizamos um aprofundamento na vida e na obra de Joan Brossa, comprovando, desse modo, sua extensa variedade e importância para a literatura mundial. Esta grande variedade da obra de Brossa permite uma rica aprendizagem da modernidade literária, e a subjetividade do poema analisado mostra as diferentes interpretações possíveis em uma Poesia Visual.

\section{Fundamentação Teórica}

\subsection{Joan Brossa}

O artista catalão Joan Brossa (1919-1998) é conhecido por sua criatividade e pelo engajamento político em suas poesias. Brossa nasceu em Saint Gervasi, Barcelona, teve uma vida em constante movimento e uma ampla abertura ao experimentalismo poético. Sua obra inclui: poemas visuais, poemas-objeto, instalações, esculturas, poemas em locais públicos, poemas cênicos e roteiros cinematográficos. Brossa não teve nenhum outro emprego, dedicando-se inteiramente à poesia, a qual ainda produziu bastante até o final de sua vida (ZILS, 2014).

O poeta permaneceu ignorado pela crítica e ausente de antologias poéticas por um longo tempo, isto devido a sua insistente produção apenas em língua catalã e à extensa variação da linguagem. O fato de ter escrito somente em catalão pode ser considerado uma prova de sua resistência à censura que se instalou na Espanha durante o governo de Franco, no período pós-

PRADO; JUNQUEIRA. Recriação e crítica: Possibilidades de tradução para o inglês do poema visual "Ode a Marx", de Joan Brossa

Belas Infiéis, v. 7, n. 1, p. 139-160, 2018. 
guerra, que proibia o uso do catalão. Brossa, por meio da utilização da língua catalã, realizava um ato de resistência à tentativa de rebaixamento de uma cultura e tradição literária e política do idioma (DAMASCENO, 2014).

Contudo, a partir de 1970, com a publicação de Poesia Rasa, Joan Brossa começa a ser reconhecido pela crítica e a ter seus livros publicados regularmente. Glória Bórdons (2000), em seu artigo "Poesia Rasa i la recepció de l'obra de Joan Brossa", afirma que esta obra é um bom compêndio dos principais temas e características do poeta em sua primeira fase. Segundo a autora, a publicação de Poesia Rasa possibilitou a Brossa ser reconhecido como guia mestre de uma nova geração, além de ter sua obra considerada pelo Guia da Literatura Catalã Contemporânea, como uma das cem melhores obras de literatura catalã do século XX.

Soma-se a isto, no decorrer das décadas de 80 e 90, a realização de várias e importantes exposições de seus poemas-objeto em instituições como a Fundação Joan Miró (Barcelona, 1986), o Centro de Arte Reina Sofia (Madri, 1991) e a Bienal de Veneza (1997). No Brasil, inclusive, a Bienal de São Paulo do ano de 1994 dedicou uma sala especial aos seus poemasobjeto. Além dessas exposições, uma chamada "Joan Brossa de Barcelona ao Novo Mundo", 142 realizada em 2006, exibiu 102 obras do poeta em itinerário que passou por Argentina, Chile e Brasil. No Brasil, a exposição aconteceu em São Paulo, em outubro e novembro de 2005, e foi acompanhada de performances relacionadas à vida de Joan Brossa. Entre elas, Ramon Farrés (2015), em seu artigo "La recepción del poeta catalán Joan Brossa en Brasil”, destaca o espetáculo entitulado "Brossa. Bros. BR.”, o qual foi apresentado no Teatro da Universidade de São Paulo (TUSP) e teve como participantes Adriana Calcanhoto, Arnaldo Antunes, Lenora de Barros, Antônio Cícero, João Bandeira e Tom Zé.

O poema-objeto, que foi destaque nestas importantes exposições, é assim chamado por “superar a prosa, extremando-a até o seu limite, ou seja, expressando os altos pelos baixos ou, se quisermos, filtrando a subjetividade através da objetividade", segundo afirma o próprio Brossa em uma de suas antologias (Brossa, 1985 In: Antología apud BANDEIRA, 1999, p. 98). Segundo Glória Bordons (1996), no artigo “La poesía objetual de Joan Brossa”, em seu processo de materialização da poesia, Brossa começou a utilizar objetos do cotidiano para aprofundar seu sentido ou representar o conceito, destacando a relação entre a palavra e a coisa.

Mesmo sendo um poeta vanguardista radical, Brossa empenha-se muito em utilizar as modalidades estróficas clássicas. Neste sentido, João Bandeira, em artigo intitulado "Joan Brossa, escova e água de chuva", afirma que Brossa empregou formas tradicionais em sua obra,

PRADO; JUNQUEIRA. Recriação e crítica: Possibilidades de tradução para o inglês do poema visual "Ode a Marx", de Joan Brossa

Belas Infiéis, v. 7, n. 1, p. 139-160, 2018. 
como o soneto, a ode e a sextina. Neste último caso, foi além do comum, produzindo a sextina alfabética, numérica, a sextina conceitual e a cibernética, cuja característica principal é traduzir em linguagem de computador as regras de construção desse tipo de poema do século XIII (BANDEIRA, 1999a, p. 99).

Outro leitor de Brossa a reforçar este viés da sua obra é Andrés Sánchez Robayna, que também reconhece em Brossa a "capacidad para hacer de un antiguo patrón compositivo medieval un verdadero surtidor de nuevas formas y significaciones" (ROBAYNA, 2001, p. 2). Robayna cita a conhecida distinção entre "inventores" e "mestres" da tradição literária feita por Ezra Pound, e considera Joan Brossa, ao lado de Foix, pertencente à segunda categoria, ou seja, àqueles que não apenas seguem a tradição, mas a enriquecem e a renovam (Ibidem, p.2).

Outra vertente da poesia de Brossa é a poesia sintética, que não segue nenhum dos padrões métricos e estróficos tradicionais. Para Robayna (2001), a poesia sintética, ou poesia essencial, chega a ser intrigante, pois o poeta não coloca limite algum na elaboração poética, baseando-se na fala cotidiana e na frase feita. Como bem percebemos nos três exemplos abaixo:

\author{
Pequena apoteose \\ A noite \\ O dia \\ Partimos o poema meio \\ a meio. \\ Gruta \\ As estalactites são concreções de \\ carbonato de cálcio. \\ Um lago de água marinha. \\ Estalagmites são concreções formadas \\ pelas gotas que caem do teto.
}

\title{
História
}

Aqui está um homem Aqui está um cadáver

Aqui está uma estátua.

(BROSSA, 1985 apud BANDEIRA, 1999, p. 98-99. Tradução de João Bandeira). Segundo Robayna (2001, p.3), "Brossa no escogía un vocabulario concreto: bastaba con reproducir fielmente el habla, de manera especial el habla de las populares". Assim, na Poesia Sintética de Brossa não havia escolha de vocabulário ou mediação literária da linguagem coloquial: o poeta escrevia do modo como falavam, principalmente, as classes populares.

PRADO; JUNQUEIRA. Recriação e crítica: Possibilidades de tradução para o inglês do poema visual "Ode a Marx", de Joan Brossa

Belas Infiéis, v. 7, n. 1, p. 139-160, 2018. 
Para Robayna (2001), com a Poesia Sintética, Brossa conseguia mostrar a importância da vitalidade da linguagem cotidiana. Tal vitalidade era a vida da própria poesia. Diz:

Lo que consiguió con ello fue no solo descubrirnos el carácter poético de todo lenguaje (...), sino también a escuchar de verdad la lengua de todos los días, a captar sus valores y sus posibilidades expresivas, así como a denunciar las fosilizaciones sociales del habla y las 'enfermedades' del lenguaje. (ROBAYNA, 2001, p. 7).

No Brasil, a primeira edição em português de um livro de Joan Brossa foi em 1998 da tradução de Poemas civis (1961), realizada por Ronald Polito e Sérgio Alcides. A obra mostra a "indissociabilidade entre a poesia e a plástica, entre a palavra e o objeto, entre o orgânico e a prótese" (BITTENCOURT, 2012, p. 223). Além disso, traz o pensamento relativo aos grandes temas da política e da civilidade, contrastando com a natureza e a realização individual, unido à linguagem coloquial (POLITO e ALCIDES apud BITTENCOURT, 2012). Como exemplificação, retiramos o poema sem título abaixo:

\section{4}

$\begin{array}{ll}\text { L'estoig } & \text { O estojo } \\ \text { és pla, la tapa } & \text { é liso, a tampa } \\ \text { és igual que la caixa; } & \text { é igual à caixa; } \\ \text { l'interior, folrat de negre. } & \text { o interior, forrado de preto. } \\ \text { Les joies. } & \text { As jóias. } \\ \text { Aquest poema té doble fons. } & \text { Este poema tem fundo falso }\end{array}$

(BROSSA, 1998, p.53. Tradução de Ronald Polito e Sérgio Alcides).

Neste poema podemos enxergar a materialização dos elementos, os versos não acabam ao final deles, escondem a complementação do sentido do mesmo modo que o estojo esconde as joias em seu fundo falso. Brossa, em Poemas civis, brinca com o leitor; enquanto faz armadilhas para a compreensão do poema, ele deixa claro o processo de construção do poema e expõe uma linguagem simples e de fácil manipulação (BITTENCOURT, 2012).

Ainda em relação ao Brasil, é importante salientar a relação entre Joan Brossa e o poeta brasileiro João Cabral de Melo Neto que surgiu a partir de 1947, quando Cabral foi trabalhar em Barcelona como cônsul do Brasil. Brossa frequentava sua casa e teve seus dois primeiros livros, Sonets de Caruixa (1950) e Em va fer Joan Brossa (1951), impressos na prensa manual que João Cabral tinha em casa (ZILS, 2014). João Cabral também escreveu o prefácio para a obra La piedra aberta (2003), no qual fala sobre a escolha de vocabulário feita por Brossa:

PRADO; JUNQUEIRA. Recriação e crítica: Possibilidades de tradução para o inglês do poema visual "Ode a Marx”, de Joan Brossa

Belas Infiéis, v. 7, n. 1, p. 139-160, 2018. 
Contrariamente a toda poesia catalã atual, preocupada sempre com o vocabulário nobre, pouco coerente, erudito ou arcaico, era na realidade mais humilde, no léxico de cozinha, de feira e de oficina, onde Brossa ia buscar o material para elaborar suas complicadas mitologias (BROSSA, 2003, p.151).

O poeta Pere Gimferrer percebe ser paradoxal um artista utilizar aspectos populares em uma vanguarda radical e se empenhar na re-elaboração das modalidades estróficas clássicas; tentar recuperar a fala e forma de vida dos menestréis, que diferem em tudo à moral do marxismo, a qual se baseia no materialismo e no homem como produto de um meio social específico e concreto; diferir da revolução surrealista, movimento do qual é considerado herdeiro no seu metiê poético. Brossa é influenciado pelas teorias do objeto desenvolvidas por artistas surrealistas como Breton, em "A crise do objeto" (1936), e Dalí, em "Objets Surréalistes" (1930).

Gimferrer (2003, p.11), aponta a utilização anacrônica do popular "em função das questões políticas sociais". O autor vê a derrota republicana da guerra espanhola, por exemplo, como uma grande influência na obra de Brossa. A guerra civil espanhola, no final da década de 30, foi um fato importante da vida do poeta catalão, pois foi atingido em um dos olhos por estilhaços de um morteiro durante uma batalha em que atuava. Brossa, em uma entrevista concedida a João Bandeira e Noemi Jaffe para a Revista Cult, afirma que esse acontecimento foi para ele um tipo de iniciação como poeta (BANDEIRA e JAFFE, 1999, apud ROSA, 2010).

Este vínculo entre a arte e a vida é discutido por Victor da Rosa em sua dissertação Segunda escrita: a profanação do objeto em Joan Brossa. Para Rosa, nenhuma metáfora em Brossa é por acidente, e o ocorrido é muito significativo para a poética do artista, que se constitui conforme possíveis "teorias do olhar". Assim:

Por um lado, o olho debilitado, imperfeito, que vê a imagem segundo uma perspectiva nebulosa e incompleta; por outro, o livro enquanto um objeto imediatamente fora da norma, da lei, que não se adequa na cena que o espera, a folha solta. (ROSA, 2010, p. 25).

Em ensaio sobre Brossa, publicado como posfácio aos 99 poemas, Ronald Polito afirma que o poeta esforça-se em associar e fazer corresponder tudo em sua obra, unificando suas tentativas artísticas. Rosa (2010) exemplifica a correspondência da obra de Brossa como a associação de problemas totalmente distintos, tais como magia, censura, arte e vida. E disserta que

PRADO; JUNQUEIRA. Recriação e crítica: Possibilidades de tradução para o inglês do poema visual "Ode a Marx", de Joan Brossa 
a ideia de correspondência torna-se ao mesmo tempo uma formulação política contra um estado de coisas em que o fundamental é a marcação de fronteiras, como foi a ditadura franquista; e, por outro lado, uma espécie de resposta aos procedimentos de vanguarda, ou seja: a possibilidade também de articular a arte para fora de seus limites de gênero e de suas técnicas tradicionais. (ROSA, 2010, p.82).

$\mathrm{Na}$ multivariedade artística, segundo Manuel Guerrero, Brossa excede todos os parâmetros:

\begin{abstract}
A extensão de sua obra é muito superior a de qualquer um de seus contemporâneos; por outro lado, trata-se de uma obra experimental que não conhece limites e que, na tradição da vanguarda histórica, amplia o âmbito poético até campos tão diversos como o teatro, o cinema ou as artes plásticas. (GUERRERO, 2003, p. 13).
\end{abstract}

Navas, autor de A Lira dos Poemas-Objetos, citado por Rira Lenira Bittencourt, afirma que Joan Brossa está além das correntes como o dadaísmo e o surrealismo. Em vez disso, encaixando em correntes pós-dadaístas, pós-surrealistas e conceituais, devido à simplicidade dos materiais do cotidiano que são utilizados, da justaposição de elementos diferentes e da importância que concedia à linguagem, respectivamente.

Focando a Poesia Visual, explica Robayna (2001) que esta se dá na obra de Brossa ao adquirir novos valores, como a metalinguagem, a despersonalização da voz lírica, a crítica social e política, o humor.

A Poesia Visual faz uma ruptura com a separação entre gêneros textuais e visuais. Para Moacy Cirne e Álvaro de Sá, ela é “o produto que se utiliza de recursos gráficos e/ou puramente visuais, de tendência caligramática, ideogramática, geométrica ou abstrata, cujo centramento gráfico-visual não exclui outras possibilidades literárias” (CIRNE; SÁ, 1978, p. 49). Portanto, a Poesia Visual pode estender-se também a gêneros verbais e sonoros.

João Bandeira (1999) explica que a Poesia Visual acontece por meio do deslocamento de palavras, letras, imagens, ligadas à leitura feita pelo título, trazendo o inesperado ou sendo surpreendido pelo óbvio. Afirma Joan Brossa que "la poesía visual no es ni dibujo ni pintura, es un servicio a la comunidad. El que se agote dependerá del talento de la gente que hace. Aquí no hay un código, estás al descubierto" (BROSSA in Fernández, 2014, p.2).

Outro autor que analisa a obra de Brossa é Rodrigo Lobo Damasceno, segundo o qual, a Poesia Visual de Joan Brossa tem composição simples e minimalista, utiliza de técnicas e estilos da arte ou expressão visual popular, que se adéqua à reprodução e distribuição em série. Damasceno (2014) observa que esta Poesia Visual pode ser compreendida em seu nível semântico mais evidente, por um cidadão apressado e desatento como acontece com pichações

PRADO; JUNQUEIRA. Recriação e crítica: Possibilidades de tradução para o inglês do poema visual "Ode a Marx", de Joan Brossa

Belas Infiéis, v. 7, n. 1, p. 139-160, 2018. 
e propagandas. Contudo, ao ser observada com maior cuidado, logo se nota a existência de algo que resiste. Conforme o autor:

\begin{abstract}
Apenas o pressentimento, apenas o fato de que haja, ali, algo que resista, já acusa a natureza artística e poética do trabalho, seu aere perenius. E não é sequer necessário que sob seu fundo falso esteja um comentário social ou político, pois a simples existência deste fundo falso indica sua resistência à banalização artística que é análoga à banalização do consumo e da linguagem - e tal resistência já é política. (DAMASCENO, 2014, p. 20).
\end{abstract}

Damasceno observa também a persistência de Brossa em relação às nomenclaturas "poema" e "poesia", mesmo que os signos verbais estejam ausentes das mesmas, e compara com a postura do poeta Nicanor Parra, cuja obra se assemelha com a do poeta catalão, diferindo inversamente, entretanto, quando chama até mesmo suas produções verbais de "antipoesia".

A seguir, três poesias visuais de Joan Brossa escolhidas para exemplificar a relação entre palavra e objeto que o poeta evidencia em sua obra:

\title{
ELEGIA AL CHE
}

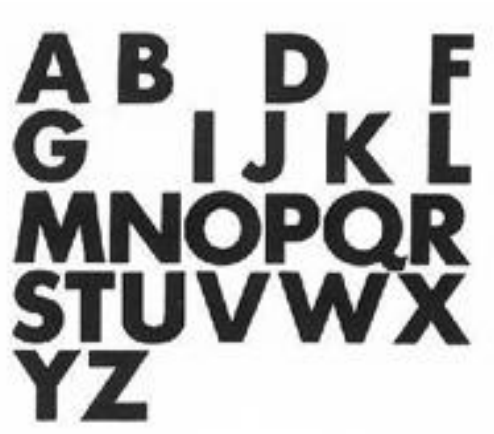

ELEGIA AL CHE

(BROSSA, 1969/78 apud BANDEIRA, 1999).

ALFA

PRADO; JUNQUEIRA. Recriação e crítica: Possibilidades de tradução para o inglês do poema visual "Ode a Marx", de Joan Brossa

Belas Infiéis, v. 7, n. 1, p. 139-160, 2018. 


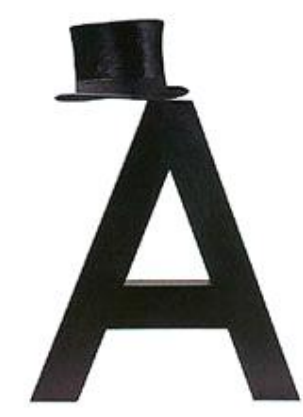

Alfa

(BROSSA, 1986. Fonte: Site Fundació Joan Brossa).

\author{
POEME-PISTOLA
}

\title{
POEMA
}

(BROSSA, 1970/78. Fonte: Site Fundació Joan Brossa).

A arte do poeta Joan Brossa é também muito conhecida pelo aspecto político explícito, e há todo um cuidado em promover a aproximação da palavra com a imagem para intensificar ainda mais a ação política, pois, segundo Rita Lenira Bittencourt, para Brossa:

A política não pode ser reduzida a uma mensagem, nem a uma militância: é um gesto constante, sofisticado e infraleve de fazer e desfazer, montar e desmontar o monstro, de acreditar em sua eficácia e ao mesmo tempo, de duvidar dela (BITTENCOURT, 2012, p.227).

Brossa sofreu com o regime ditatorial do governo franquista, e em inúmeros de seus poemas critica de forma sutil e ambígua o autoritarismo praticado pelo governante. Em um de seus poemas sem título de 1969 consta:

A censura suprimiu nove poemas:

sinal de que os outros não valem nada

PRADO; JUNQUEIRA. Recriação e crítica: Possibilidades de tradução para o inglês do poema visual "Ode a Marx”, de Joan Brossa

Belas Infiéis, v. 7, n. 1, p. 139-160, 2018. 
Em seus poemas visuais podemos perceber seu engajamento político com uma visada socialista-marxista. A influência do pensamento de Karl Marx (1818-1883) se estendeu por todo século XIX e XX. Seu impacto no mundo intelectual e literário é muito grande e deixará marcas no pensamento de Joan Brossa, como veremos em seguida.

\subsection{O Marxismo}

O Marxismo é um movimento político, social, econômico e filosófico que se interessa por todas as questões que concernem aos problemas do homem, tais como: sua origem, seu lugar no universo, sua função sobre a terra, seu destino histórico, sua existência e possibilidades de exercício de sua liberdade e suas relações com a ideia de Deus (BAAS, 1958). Conforme o pensamento de Karl Marx, os homens começam a se diferenciar dos animais a partir do momento em que produzem seus meios para subsistir (MARX apud BAAS, 1958). Este é o princípio do materialismo marxista, para o qual não há teoria sem prática ou filosofia sem método de ação.

Emile Baas, teórica do marxismo, aponta que para Marx a finalidade da teoria seria a de explicar a realidade da situação em que se encontra o homem no mundo em que vive, fornecendo, deste modo, armas à prática, ou seja, equipando a ação política revolucionária. Segundo a autora, na visão marxista a filosofia tem seu desenvolvimento a partir da ação revolucionária, pois esta transforma o ambiente, revelando novos aspectos nos quais a filosofia se enriquece. Acontece, dessa maneira, a relação de troca entre o proletário e a filosofia: "Filosofia que se orienta para a ação, ação que pressupõe a filosofia, mas que, ao mesmo tempo, a auxilia e completa" (BAAS, 1958, p.34).

O materialismo histórico possibilitou o estudo e as modificações das condições sociais das massas, que, na visão marxista, são os atores mais importantes da história, e até então eram negligenciadas (LENIN apud BAAS, 1958).

Entre as principais marcas do marxismo, o autor Francisco Sodero Toledo (2001), destaca: a contradição como o motor da história, ou seja, as chamadas lutas de classes; a universalização histórica, em que cada homem é visto como ser da história universal e não ser local; a maneira de produção organizada pelo homem, chamada por Mezaros de "o desenvolvimento universal das forças produtivas"; e a introdução do método dialético de obtenção de conhecimento. Marx aplicava, portanto, uma visão dialética à natureza e à

PRADO; JUNQUEIRA. Recriação e crítica: Possibilidades de tradução para o inglês do poema visual "Ode a Marx", de Joan Brossa

Belas Infiéis, v. 7, n. 1, p. 139-160, 2018. 
sociedade, introduzindo o conceito da filosofia da práxis, na qual o conhecimento é aplicado como ferramenta para transformar a realidade. (TOLEDO, 2001).

Quanto à relação do marxismo com a literatura, segundo Terry Eagleton, em seu livro Marxismo e crítica literária (2011), Karl Marx não desconsiderava a importância da mesma, embora seja mais conhecido por suas obras políticas e econômicas. Conforme o autor, "a arte e literatura faziam parte do próprio ar que Marx respirava, como um intelectual alemão formidavelmente culto dentro da grande tradição clássica da sociedade" (EAGLETON, 2011, p. 12).

A crítica marxista encoraja o escritor a realizar sua arte de forma engajada na causa do proletariado. Eagleton (2011) afirma que, apesar desse encorajamento, Marx acreditava que as obras literárias não deveriam ser somente utilitárias e politicamente prescritivas, mas que também tinham um fim em si mesmas, conforme podemos perceber em uma de suas observações: "Milton produziu Paraíso Perdido pelo menos motivo que um bicho da seda produz seda. Era uma atividade da sua natureza" (MARX em Teorias da mais valia apud EAGLETON, 2011, p. 84).

150 Podemos compreender, desse modo, que para o marxismo é importante que a arte traga questões políticas, forças e potencias do proletário, mas de maneira discreta, não assumindo o partidarismo e influenciando diretamente seus leitores (EAGLETON, 2011).

\section{Análise do corpus}

\section{1 "Ode a Marx": Possibilidades de tradução para a língua inglesa}

Inspirado pela visão dialética de Karl Marx, em que sujeito e objeto atuam um sobre o outro, Joan Brossa produz o poema “Ode a Marx” (1983), no qual aparece a imagem de uma grande onda ao lado de uma letra $\mathrm{X}$ em grande proporção.

PRADO; JUNQUEIRA. Recriação e crítica: Possibilidades de tradução para o inglês do poema visual "Ode a Marx", de Joan Brossa

Belas Infiéis, v. 7, n. 1, p. 139-160, 2018. 

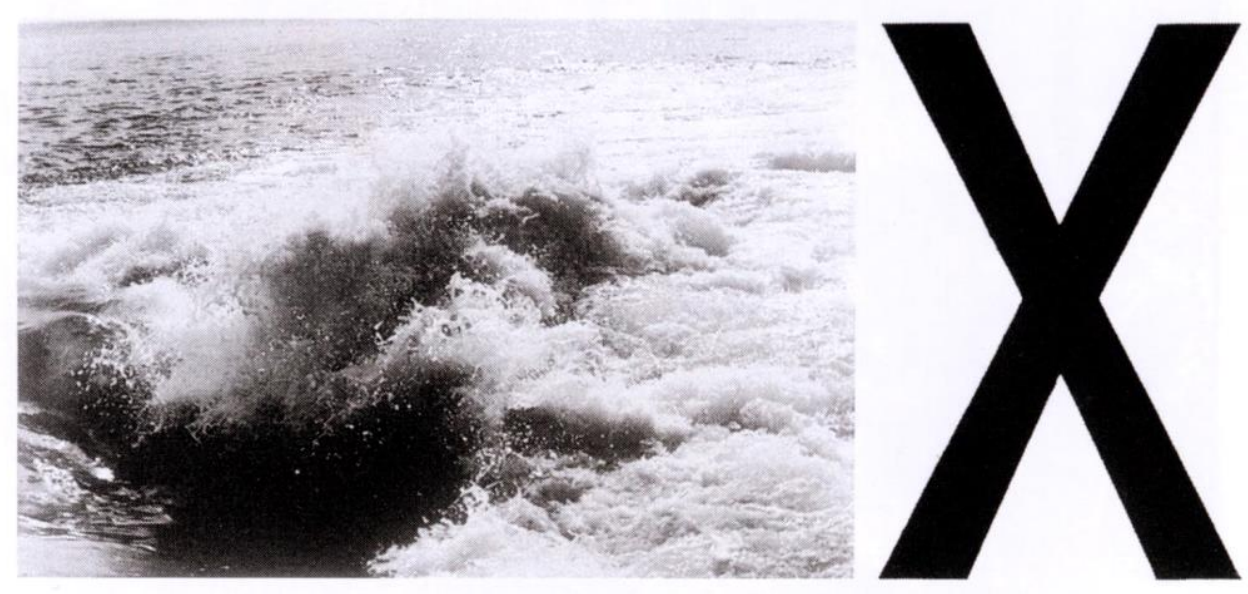

(BROSSA, 1983. Fonte: Site Fundació Joan Brossa).

Como diz João Bandeira:

Pode-se ler o nome de quem passou a história sendo capaz de pensamento e ação comparáveis à força, profundidade ou fertilidade do mar, que aqui se joga contra um signo de interdição. (BANDEIRA, 1999, p.102)

Elys Zils ressalta também a grande dimensão simbólica da água em diferentes culturas:

Além de fonte de vida e movimento, água é vista como meio de purificação. Podemos, então, interpretar o poema como uma força em busca da purificação e renovação social, política e econômica ao lembrarmos das ideias pregadas por Karl Marx. (ZILS, 2014, p.264)

Segundo o Dicionário de termos literários, de Massaud Moisés, o gênero formal "ode" tem origem grega e passou por diversas transformações históricas, não perdendo, entretanto, a sua atmosfera grave, solene, próxima do drama e da poesia épica. Pode-se classificá-la de diferentes modos a partir da matéria tratada e da forma apresentada. A “Ode a Marx" de Joan Brossa se aproximaria da ode filosófica, moral ou sáfica quanto ao tema, e à ode irregular ou livre por não seguir nenhuma modalidade métrica, sendo ainda, uma ode visual.

Podemos interpretar de muitas outras maneiras a imagem da onda se quebrando e da letra X, e também atribuindo características do pensador Karl Marx a estes signos. Para Toledo (1997), no princípio dialético a contradição aparece como o motor do processo de evolução. É

PRADO; JUNQUEIRA. Recriação e crítica: Possibilidades de tradução para o inglês do poema visual "Ode a Marx", de Joan Brossa

Belas Infiéis, v. 7, n. 1, p. 139-160, 2018. 
possível, assim, ver no mar a força da natureza, que atua sobre o homem, ao lado de um signo de contradição: juntos, força e luta poderão levar ao desenvolvimento universal.

Partindo destes princípios analisados no decorrer do artigo, propomos como via crítica uma tradução para o inglês do citado poema visual. Ao pensar no poema sendo lido/visto por um leitor em língua inglesa, percebemos a necessidade de mudança dos signos presentes no poema de Joan Brossa.

O filósofo, escritor e tradutor Johann Gottfried Herder (1744-1803) já afirmava que “ninguém pensa além do idioma” (HERDER, 1943 In Spiegel der Humanitat apud RÓNAI, 2012, p. 14), ou seja, algumas ideias só podem ser entendidas por alguém que compreenda a língua-alvo. O leitor da língua inglesa não compreenderia a palavra "mar" como oceano. Portanto, ao ver a imagem do mar, não identificaria a ligação com o pensador Marx. Pensamos aqui, em um leitor mediano da língua inglesa, que não tenha conhecimento profundo da língua catalã, entretanto, mesmo pensando em um leitor que conheça este idioma, o objetivo dessa proposta é tentar trazer para sua língua materna os significados produzidos por Joan Brossa no poema "Ode a Marx".

152 Em catalão, a palavra mar é escrita "mar", assim como em português e espanhol. Em francês mar se grafa "mer" e aproxima-se um pouco do original, mas em inglês "sea" destoa muito da relação "MAR/MARx".

É importante aqui ressaltar a relação entre a imagem e o signo verbal que ocorre a partir da leitura deste poema. Até mesmo a nomenclatura "poesia" com a qual Brossa denomina suas obras visuais, como já comentamos anteriormente, pode ser justificada pela Semiologia no que se refere à ligação direta do signo extralinguístico ao signo verbal.

Em estudo realizado por Izidoro Blikstein, intitulado Kaspar Hauser ou A Fabricação da Realidade (1986), o autor afirma que "o fato de o referente ser extralingüístico não significa que deva ficar fora da lingüística; ele simplesmente está situado atrás ou antes da linguagem, como um evento cognitivo, produto da nossa percepção" (BLIKSTEIN, 1986, p.39). Segundo Blikstein, linguistas modernos consideram a língua como "organizadora da estrutura conceitual do universo" ou como a tese clássica feita pelo filósofo W. Von Humboldt de que a língua é "o órgão construtor do pensamento.” (HUMBOLDT apud Blikstein, 1986. p. 40).

O filósofo francês Roland Barthes, encarando a semiologia como uma parte da linguística, considera que

PRADO; JUNQUEIRA. Recriação e crítica: Possibilidades de tradução para o inglês do poema visual "Ode a Marx", de Joan Brossa

Belas Infiéis, v. 7, n. 1, p. 139-160, 2018. 
Parece cada vez mais difícil conceber um sistema de imagens ou objetos, cujos significados possam existir fora da linguagem: perceber o que significa uma substância é, fatalmente, recorrer ao recorte da língua: sentido só existe quando denominado, e o mundo dos significados não é outro senão o da linguagem (BARTHES apud Blikstein, 1986, p. 41).

Nesta visão, ao nos depararmos com a imagem do mar, teríamos como significante a palavra "mar" e como significado todas as interpretações possíveis de serem realizadas a partir dos conceitos de mar que conhecemos quando inseridos em determinada cultura. Por isso a dificuldade de compreensão de um leitor que não conheça o idioma de partida de uma obra.

Como embasamento teórico para o processo de tradução, nos aproximamos do pensamento de Haroldo de Campos (São Paulo, 1929- 2003), importante tradutor e pensador da literatura no Brasil. Em seu famoso ensaio/manifesto, publicado em 1962, "Da Tradução como Criação e como Crítica", citando Albercht Fabri, afirma que a linguagem literária é a criação da sentença que não tem conteúdo além da estrutura, isto é, a sentença absoluta. Essa sentença é perfeita e, assim, não pode ser traduzida, pois seriam separados sentido e palavra. A partir disso, Haroldo de Campos considera que a tradução de textos literários sempre é recriação, pois "não se traduz apenas o significado, traduz-se o próprio signo, ou seja, sua fisicalidade, sua materialidade" (CAMPOS, 2013, p.35).

Pensando desse modo, decidimos substituir o sobrenome Marx pelo primeiro nome Karl. Obtivemos a possibilidade de utilizar a palavra "car", que significa carro na língua inglesa, por possuir som idêntico ao início do nome de Karl, mais a letra L. Criamos assim, analogamente, "MAR/MARx" - "CAR/KARl”.

Pensamos em trabalhar com a imagem de um carro por remeter à ideia de avanço que o pensamento marxista contém, além da ideia de movimento, que busca um novo lugar, ou seja, o desenvolvimento. Assim, nós mantemos um pouco do sentido de força presente no mar. $\mathrm{Na}$ visão dialética, concebida por Hegel e aplicada por Marx, os homens para sobreviverem precisam transformar a natureza, atuar sobre o mundo em que vivem (TOLEDO, 2001). A partir dessa visão, o carro representa a transformação praticada pelo indivíduo na sociedade, o objeto que o levará a seu desenvolvimento, produzido por seu trabalho. Segundo Karl Marx: "O homem que trabalha é como que um gesto de natureza. Movimenta forças e membros a fim de assimilar a matéria e dar-lhe uma forma útil à vida" (MARX in Le Capital I apud BASS, 1958).

Estando assim determinado o carro como signo do poema, surgiu a dúvida de qual marca escolher. Pensamos, primeiramente, em um carro que remetesse à nacionalidade do pensador Karl Marx; o leitor encontraria neste fato mais uma informação como importante referência ao

PRADO; JUNQUEIRA. Recriação e crítica: Possibilidades de tradução para o inglês do poema visual "Ode a Marx", de Joan Brossa

Belas Infiéis, v. 7, n. 1, p. 139-160, 2018. 
filósofo. Determinamos desta forma, utilizar uma marca alemã: Volkswagen. "Volks" significa "povo" e "Wagen" significa carro, em alemão. O carro mais popular da Alemanha é o Fusca, pertencente a esta mesma marca. Escolhemos então um Fusca, o carro mais popular, para trazer o pensamento de Marx de convocar os proletários do mundo, as grandes massas, pela luta do socialismo, a luta por uma nova classe.

Suscitou-se, então, a questão da cor do carro. Precisávamos de uma cor que trouxesse ainda mais significados ao objeto, que atuaria também como um símbolo neste poema. Decidimo-nos pelo vermelho, como referência à bandeira vermelha do comunismo, que simboliza o sangue e martirização da classe operária.

Escolhemos trabalhar com uma imagem colorida, apesar de o poema original de Brossa ser feito em preto e branco. Esta escolha se dá ao fato de considerarmos importante a cor vermelha como símbolo que facilitaria a compreensão do leitor da referência ao comunismo. Entretanto, se fosse necessário, acreditamos que sem o recurso das cores também seria possível a um leitor de nossa tradução identificar as características das ideias de Karl Marx presentes na imagem do carro, somada à representação da letra L .

154 Em relação a qual seria o modelo do carro na imagem, consideramos a possibilidade de um Fusca moderno, para evidenciar ainda mais a nossa tradução como uma releitura sincrônica da obra original. Acreditamos, contudo, que o Fusca tradicional causa um maior impacto visual por ser mais conhecido popularmente do que o novo, trazendo uma melhor compreensão da referência do carro mais popular à ideia da luta das massas na visão de Marx.

Definidas estas questões, preocupamo-nos em como representar a letra L, pois esta perdia muito do sentido de interdição, bloqueio e luta presente na letra X. Era necessário criar uma forma de trazer alguns destes significados também para a letra L.

Inicialmente, imaginamos uma letra $\mathrm{L}$ em formato de chave, que remete muito ao pensamento de Joan Brossa a respeito da palavra como chave, exposto até mesmo em uma de suas poesias visuais concebida em 1971 e concluída em 1982. Este poema mostra as letras do alfabeto como chave, com a ideia de que nas letras está o segredo que pode abrir as portas para novas possibilidades (ZILZ, 2014, p. 269).

PRADO; JUNQUEIRA. Recriação e crítica: Possibilidades de tradução para o inglês do poema visual "Ode a Marx", de Joan Brossa 


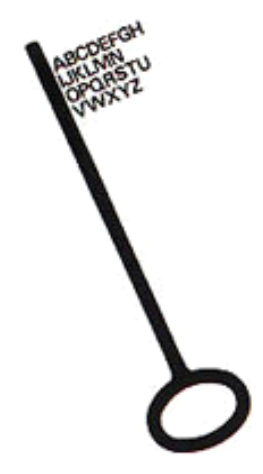

(BROSSA, 1982. Fonte: Site Fundació Joan Brossa).

Pensamos em produzir o nome Karl com um L em chave, para simbolizar o segredo que possibilitaria avanço do pensamento que impulsionava a luta política por mudanças. Deste modo, nossa primeira tradução seria o nome Karl formado por um Fusca vermelho, "car”, ao lado de uma chave em formato da letra L. Esta alternativa de tradução nos agrada por dialogar com a imagem do carro e com as ideias de Brossa a respeito da força da poesia como chave.

Entretanto, a ideia de interdição presente no símbolo $\mathrm{X}$ do poema original de Brossa ainda não havia sido recuperada. Era esta a nossa escolha principal: o X como bloqueio e interdição.

Apesar de nossa principal interpretação do signo X ser esta, não se pode desconsiderar a grande simbologia que o $\mathrm{X}$ tem na cultura ocidental de marcar ou assinalar uma alternativa, fazer uma escolha. É possível, nessa visão, interpretar a "Ode a Marx" como a representação da escolha pela força e profundidade presente no pensamento de Karl Marx que é metaforizado pelo mar. Uma possibilidade de tradução que obtivemos a partir desta interpretação seria a da letra L como marcador de uma escolha. Pensamos, assim, em representar a letra L em outro tipo de símbolo usado para assinalar uma alternativa.

PRADO; JUNQUEIRA. Recriação e crítica: Possibilidades de tradução para o inglês do poema visual "Ode a Marx", de Joan Brossa

Belas Infiéis, v. 7, n. 1, p. 139-160, 2018. 


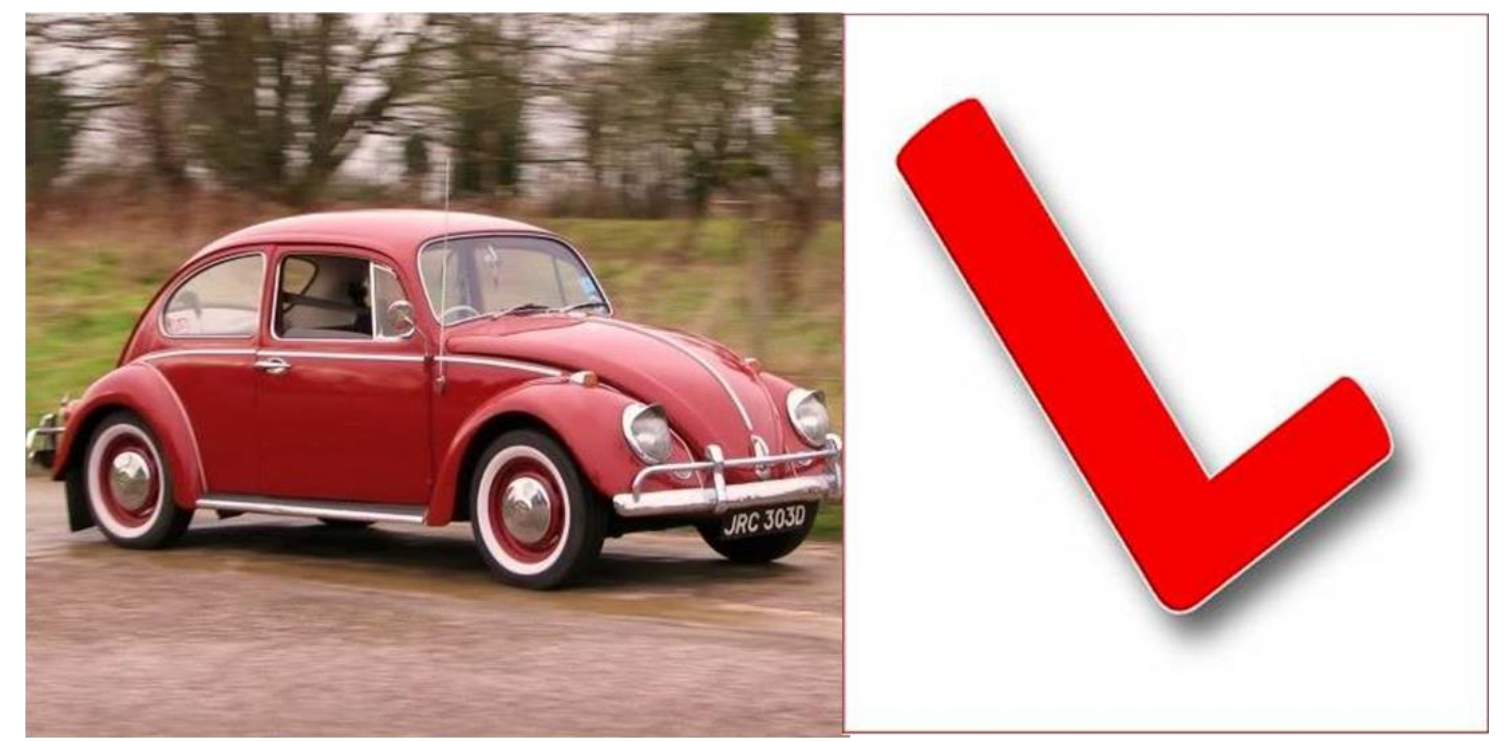

Entretanto, não nos aprofundamos nesta possibilidade de tradução, somente foi verificado que em um processo de traduzir uma obra literária existem diferentes caminhos possíveis que dependem da interpretação de quem a traduz.

Conforme Paulo Rónai, no artigo "Traduzir o Intraduzível”, as dificuldades de um processo de tradução não podem ser limitadas e "não há problema de tradução definitivamente resolvido" (RÓNAI, 2012, p.19). Pensando dessa maneira, podemos pensar em formas distintas de tradução para uma mesma obra, já que a cada mudança poderemos alcançar e recuperar um novo sentido presente na obra original.

Colocamo-nos a buscar outra solução para esta tradução que contivesse o símbolo de bloqueio, deste modo, imaginamos uma letra L em uma placa de trânsito. Esta escolha dialoga com a imagem do carro, ao mesmo tempo em que traz a representação de proibição. Este símbolo seria então a interdição do pensamento presente na imagem do carro. A força da luta pelo avanço, pelo desenvolvimento das classes operárias que se depara com a restrição presente na placa.

Ainda segundo Paulo Rónai, quando se trata de tradução precisamos "por um esforço da imaginação, meter-nos na pele do autor e dizer o que ele diria se falasse a nossa língua" (2012, p.25). Assim, tentamos imaginar o que Joan Brossa faria se fosse criar o poema, na língua inglesa. Finalizadas as escolhas, embasadas nas teorias da tradução de Haroldo de Campos e Paulo Rónai e apoiadas no estudo sobre o marxismo e sobre a visão artística do poeta Joan Brossa, as duas traduções recriadas ficaram do seguinte modo:

PRADO; JUNQUEIRA. Recriação e crítica: Possibilidades de tradução para o inglês do poema visual "Ode a Marx", de Joan Brossa

Belas Infiéis, v. 7, n. 1, p. 139-160, 2018. 
"Ode a Karl"
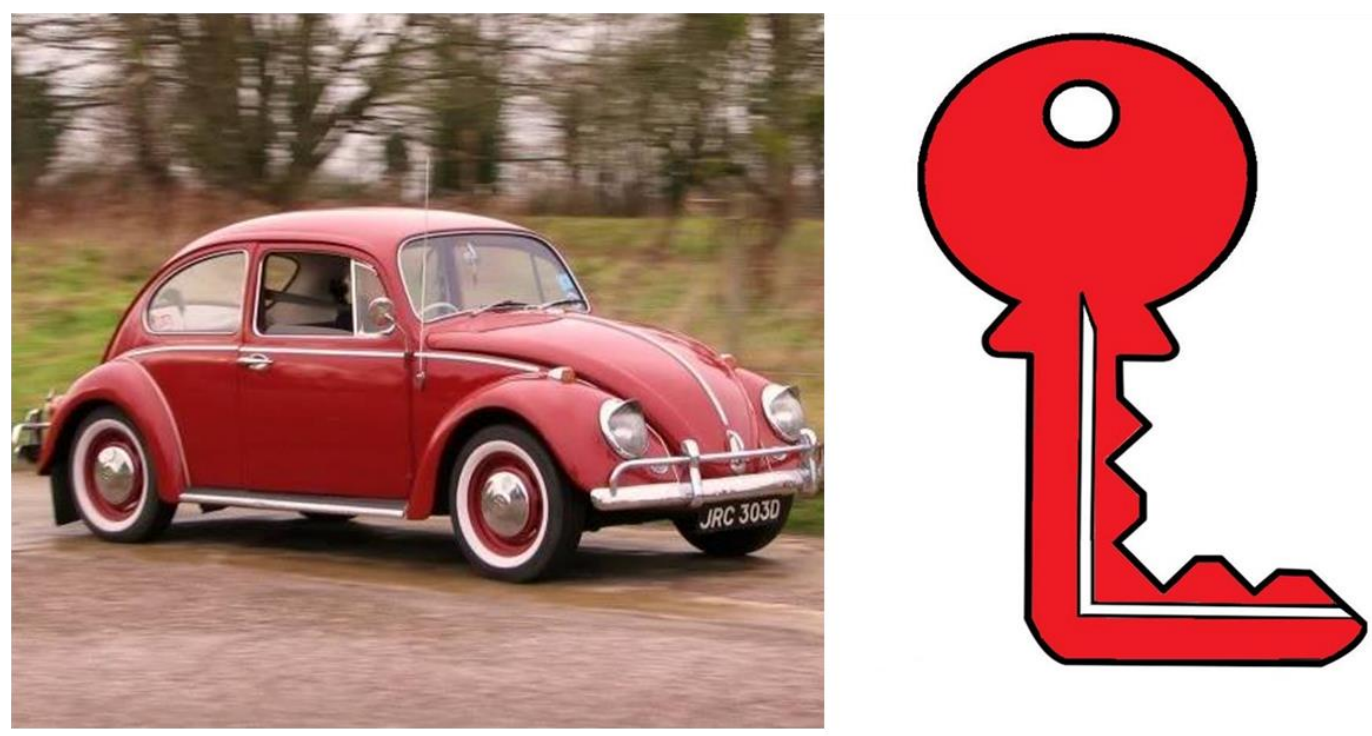

"Ode a Karl"
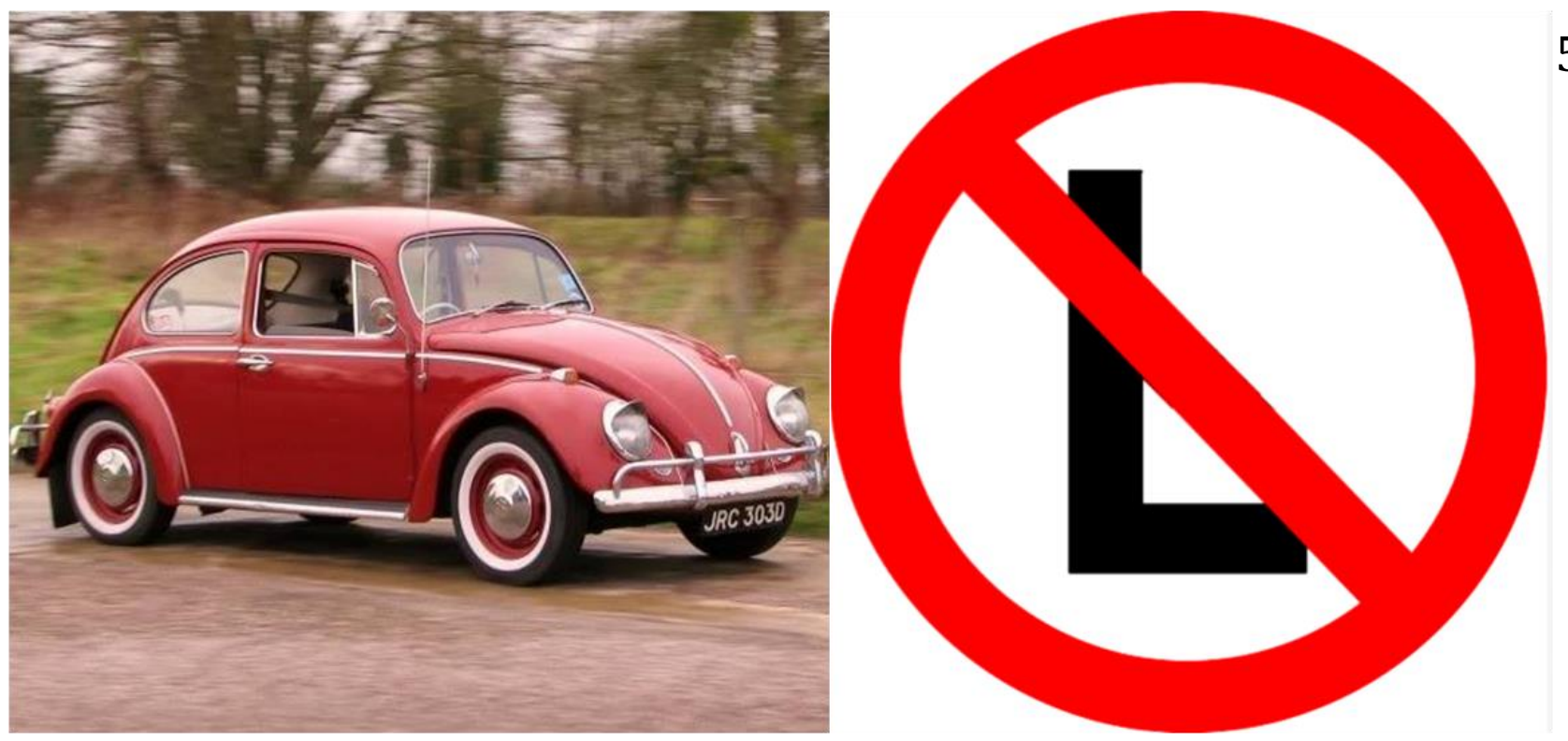

\section{Considerações finais}

PRADO; JUNQUEIRA. Recriação e crítica: Possibilidades de tradução para o inglês do poema visual "Ode a Marx", de Joan Brossa

Belas Infiéis, v. 7, n. 1, p. 139-160, 2018. 
Concluímos que a tradução é também uma maneira efetiva de aprofundamento crítico na obra de um autor, ao passo que propicia uma leitura melhor e mais atenta.

Conforme afirma Haroldo de Campos (2013), durante o processo de traduzir uma obra literária, o tradutor encontra a necessidade constante de "compensar". Este seria um jogo de perde-ganha, pois ao mesmo tempo em que, com uma determinada escolha, recuperamos um sentido do poema original, podemos perder outro significado. Em nossa tradução, com a escolha da imagem do carro, "car", colocada ao lado da letra L, nós alcançamos a pronúncia exata do nome Karl; entretanto, não conseguimos recuperar sua idêntica grafia como fez Brossa ao representar Marx por “mar" + X. Desse modo, tivemos uma perda no sentido gráfico do poema. Porém, pudemos alcançar outro significado importante que traz mais um sentido para a poesia por meio da utilização da cor vermelha, que representa a bandeira comunista, em nossa tradução.

É importante ressaltar que nossa intenção ao traduzir este poema visual não foi a de realizar um trabalho como tradutores ou poetas, mas a de nos aprofundarmos em uma leitura crítica acerca da criação de um grande poeta. Esperamos que este trabalho seja uma abertura para novos caminhos de estudo a respeito da obra do extraordinário artista Joan Brossa.

"Ode a Karl Marx”:
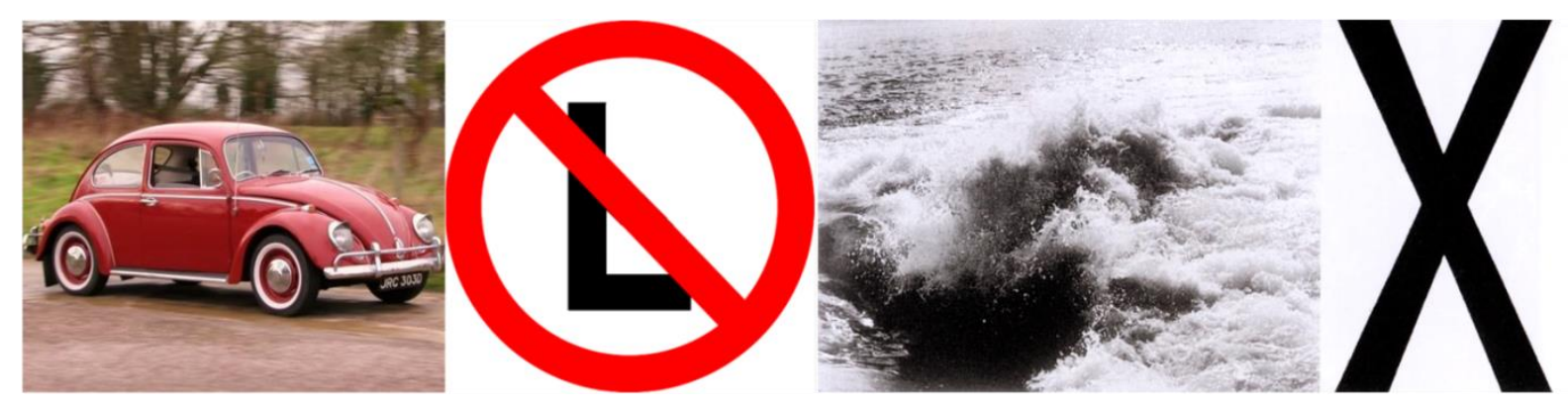

\section{REFERÊNCIAS BIBLIOGRÁFICAS}

BANDEIRA, João. Joan Brossa, escova e água de chuva. Novos Estudos,São Paulo, CEBRAP, n.55, novembro 1999a, p. 97-103.

BANDEIRA, João. Duas vezes quarenta. Cult, São Paulo, Editora Bregantini. No19, ano II, 1999b.

BAAS, Emile. Introdução Crítica ao Marxismo. Tradução do P. Fernando Bastos de Ávila, S.J. Rio de Janeiro: Livraria Agir Editora, 1958.

PRADO; JUNQUEIRA. Recriação e crítica: Possibilidades de tradução para o inglês do poema visual "Ode a Marx", de Joan Brossa

Belas Infiéis, v. 7, n. 1, p. 139-160, 2018. 
BASSNETT, Susan. Estudos da tradução. Tradução de Vivina de Campos Figueiredo. Lisboa, Portugal: Fundação Calouste Gulbenkian, 2003.

BERMAN, Antoine. A prova do estrangeiro: cultura e tradução na Alemanha romântica: Herder, Goethe, Schlegel, Novalis, Humboldt, Schleiermacher, Hölderlin. Tradução de Maria Emília Pereira Chanut. Bauru, SP: EDUSC, 2002.

BITTENCOURT, Rita Lenira. A política de deslocamentos nos 'Poemas civis' de Joan Brossa. Organon (UFRGS), v. 27, p.221-232, 2012.

BLIKSTEIN, Izidoro. Kaspar Hauser ou A Fabricação da Realidade. São Paulo: Editora Cultrix: Editora da Universidade de São Paulo, 1983.

BÓRDONS. Glória. Poesia Rasa i la recepció de l'obra de Joan Brossa. Barcelona: KRTUDepartament de Cultura de la Generalitat de Catalunya, Fundació Joan Brossa i Fundació Joan Miró, 2000, p. 358-363.

BÓRDONS, Glória. La poesía objetual de Joan Brossa. Barcelona, Poiesis. Revista de crítica y creación literaria, 1996. núm. 3, p. 22-30.

BROSSA, Joan. 99 poemas. Org. ROSA, Victor; POLITO, Ronald. Tradução: Ronald Polito. São Paulo: Annablume/Demônio Negro, 2009.

BROSSA, Joan. La piedra aberta (antologia bilíngue). Barcelona: Gabaxia Gutenberg, 2003.

CAMPOS. Haroldo de. Da tradução como criação e como crítica. In: . (Org.).

Metalinguagem e outras metas. São Paulo: Perspectiva, 2013, p. 31- 48.

CIRNE, M.; SÁ, A. de. Do modernismo ao poema-processo e ao poema experimental: teoria e prática. In: Revista de Cultura Vozes, Petrópolis, v.72, n. 1, p.0-49, 1978.

DAMASCENO, Rodrigo. Joan Brossa: ética, política e visualidade. In: Horácio Costa. (Org.). O poema moderno: releituras e intersecções. 1 ed. São Paulo: Lumme Editor, 2014, p. 343375.

EAGLETON, Terry. Marxismo e Crítica Literária. Tradução: Matheus Corrêa. São Paulo: Editora UNESP. 2011.

FARRÉS, Ramon. La recepción del poeta catalán Joan Brossa en Brasil. In: Meta. Volume 60, número 1, Avril, 2015, p. 158-172.

FERNÁNDEZ, F. Entrevista imaginária a Joan Brossa. Arte Literal, Cuidad Guayana, 2014. Disponível em: <http://www.arteliteral.com/arteliteral_20/arte/brossa2.htpm> Acesso em: 03/05/2018.

GIMFERRER, Pere. Liminar. In: BROSSA, Joan. La piedra aberta. Op. Cit., 2003, p.11. GUERRERO, Manuel. La piedra aberta. Tradução e prólogo: Rita Lenira Bittencourt. Barcelona: Galáxia Gutenberg, 2003, p. 13.

PRADO; JUNQUEIRA. Recriação e crítica: Possibilidades de tradução para o inglês do poema visual "Ode a Marx", de Joan Brossa

Belas Infiéis, v. 7, n. 1, p. 139-160, 2018. 
POLITO, R. e ALCIDES, S. Sobre a tradução. In: BROSSA, Joan. Poemas civis. São Paulo: 7 Letras, 1998, p. 280. Tradução: Ronald Polito e Sérgio Alcides.

ROBAYNA. Andrés Sánchez. La poesía sintética de Joan Brossa. 2001. Disponível em: <http://www.uoc.edu/jocs/brossa/articles/robayna.html>. Acesso em: 03/05/2018.

RÓNAI. Paulo. Escola de tradutores. Rio de Janeiro: Editora José Olympio, 2012.

ROSA, Victor da. Segunda escrita: A profanação do objeto em Joan Brossa. 145 fls. Dissertação (Pós-graduação) - Teoria Literária, Universidade Federal de Santa Catarina. Florianópolis. 2010.

TOLEDO, Francisco Sodero. Marxismo: Uma Reflexão. In: Revista Ideias e Argumentos, Lorena, v. 2/3, p. 96-113, 2001.

ZILS, Elys Regina. A poesia visual de Joan Brossa. In: Revista Versalete, Curitiba, vol.2, nº 3 , jul.-dez. 2014.

\footnotetext{
${ }^{\text {i }}$ Raíssa Maria Ribeiro do PRADO - Graduada em Letras - Português e Inglês (2016) pelo Centro Universitário Teresa D’Ávila. Lorena, São Paulo, Brasil. Lattes: http://lattes.cnpq.br/8718464279530466 E-mail: raissa.ribeiro16@hotmail.com

160 ii João Francisco Pereira Nunes JUNQUEIRA - Doutorando e Mestre (2012) em Letras pela Universidade Estadual Paulista Júlio de Mesquita Filho. Graduado em Letras (2009) pela mesma universidade. Docente do Centro Universitário Teresa D’Ávila. Lorena, São Paulo, Brasil. Lattes: http://lattes.cnpq.br/2452650179195644 E-mail: jfpnjunqueira@yahoo.com.br
} 